\title{
USO DE COMPOSTO DE RESTOS DE ALIMENTOS DE UAN (UNIDADE DE ALIMENTAÇÃO E NUTRIÇÃO) NA PRODUÇÃO DE ALFACE
}

\author{
Cleicimar Gomes Costa ${ }^{1}$ \\ Kátia Cristina da Silva ${ }^{2}$ \\ Vinícius Faúla de Aguiar ${ }^{3}$ \\ Luiz Carlos Gomes de Azevedo ${ }^{4}$ \\ Alba Nise Merícia Rocha Santos ${ }^{5}$ \\ Alisson José Eufrásio de Carvalho ${ }^{6}$
}

Resumo: É considerável a quantidade de alimentos devolvida no prato/bandeja, que será destinado ao aterro sanitário, não se dispondo de uma forma conveniente de reaproveitamento. Promover o tratamento de tais resíduos é uma prática relevante para a sociedade, em contrapartida, promove a geração de insumos orgânicos para a agricultura. Doses de composto orgânico a partir do resto ingesta da UAN do IFMG - São João Evangelista foram avaliadas na produtividade da alface americana. O delineamento utilizado foi em blocos casualizados com quatro repetições, sendo os tratamentos constituídos por cinco doses de composto orgânico (0,0;15,15; 30,3; 60,6 e 120 t.ha-1 de matéria seca). Houve aumento significativo no número de folhas, massa seca e fresca da parte aérea que respondeu acentuadamente ao aumento das doses de composto utilizado. A massa fresca comercial total evidenciou aumento com as doses de composto, na qual a produtividade máxima de $1350 \mathrm{~g}^{\text {planta-1}}{ }^{-1}$, foi obtida com a dose de 112,5 t.ha-1 do composto orgânico. Para massa seca, a máxima produtividade $97 \mathrm{~g} \mathrm{planta}^{-1}$, foi obtida com a dose de 116,4 t.ha-1. Através dos resultados obtidos pode-se concluir que o uso de 120 t.ha-1 de composto orgânico aplicado na produção da alface proporciona incrementos na produtividade, sendo viável sua utilização, além de uma forma sustentável trazendo benefícios para o solo e meio ambiente.

Palavras-chave: Resto ingesta; Adubação; Olericultura.

\footnotetext{
1 Bacharelado em Agronomia/ Instituto Federal de Educação Ciência e Tecnologia de Minas Gerais - Campus São João Evangelista - MG, Brasil. E-mail: cleicimar_gomesje@hotmail.com.

${ }^{2}$ Bacharelado em Agronomia/ Instituto Federal de Educação Ciência e Tecnologia de Minas Gerais - Campus São João Evangelista - MG, Brasil. E-mail: katiaeaf@yahoo.com.br.

${ }^{3}$ Bacharelado em Agronomia/ Instituto Federal de Educação Ciência e Tecnologia de Minas Gerais - Campus São João Evangelista - MG, Brasil. E-mail: vinicius.aguiar.agr@gmail.com.

${ }^{4}$ Bacharelado em Agronomia/ Instituto Federal de Educação Ciência e Tecnologia de Minas Gerais - Campus São João Evangelista - MG, Brasil. E-mail: luizcap2011@hotmail.com.

${ }^{5}$ Bacharelado em Agronomia/ Instituto Federal de Educação Ciência e Tecnologia de Minas Gerais - Campus São João Evangelista - MG, Brasil. E-mail: albarocha@live.com.

${ }^{6}$ Bacharelado em Agronomia/ Instituto Federal de Educação Ciência e Tecnologia de Minas Gerais - Campus São João Evangelista - MG, Brasil. E-mail: alisson.carvalho@ifmg.edu.br.
} 